\title{
A study of the ability of the deformation of titanium sheet by hot single point incremental forming technology
}

\author{
Tran Trong Hy, Nguyen Tan Hung, Vo Tuyen, Le Khanh Dien, Pham Huy Hoang, \\ Nguyen Thanh Nam, Nguyen Ngoc Phuong
}

\begin{abstract}
Hot Single Point Incremental Forming (HOT SPIF) is a new technology of forming a metal sheet at high temperatures, especially for hard, high strength materials that are difficult to perform at normal temperatures such as Titanium and other materials. The paper presents the application of simulation method to determine the ability of the deformation of Titanium sheet through the angle of deformation $\alpha_{\max }$ of the lateral profile of the model under the influence of tool diameter $D$ $(\mathrm{mm})$, step in the direction $\mathrm{z}$ of the tool $\mathrm{Vz}(\mathrm{mm})$, the velocity of the tool $\mathrm{Vxy}(\mathrm{mm} / \mathrm{min})$, the temperature $\mathbf{T}\left({ }^{0} \mathrm{C}\right)$. The content of this paper consists of the analyzing the influence of these 4 above parameters by building a finite element analyzing (FEA) model to determine the ability of deformation or the maximum lateral angle of forming and to compare the accuracy of FEM model to the one of Computer-aided design (CAD) model. The paper studies the influences of the 4 parameters to the ability to form of Titanium sheet by HOT SPIF.
\end{abstract}

This paper is submitted on 15 June 2017 and is accepted on 20 September 2017.

This research is supported by DCSELAB HCMUT, VNUHCM and funded by Vietnam National University Ho Chi Minh City (VNU-HCM) under grant number C2017-20b-02. We appreciate highly the great help of the laboratory in performing the research.

Tran Trong Hy, Nguyen Tan Hung, Vo Tuyen, Le Khanh Dien, Digital Control and System Engineering Laboratory, DCSElab, Ho Chi Minh City University of Technology - VNUHCM ,Vietnam (email: thuhien@dcselab.edu.vn)

Pham Huy Hoang, Nguyen Thanh Nam, Ho Chi Minh City University of Technology - VNU-HCM, Vietnam (email: phhoang@hcmut.edu.vn)

Nguyen Ngoc Phuong, Ho Chi Minh City University of Technology Education, HCMUTE, Vietnam
Index Terms - HOT SPIF, deformation, Titanium sheet, ability of deformation, FEA, CAD model

\section{INTRODUCTION}

Tn small or single batch productions of forming $\mathbf{I}_{\text {metal sheet products, SPIF technology is }}$ selected in forming new products than other traditional methods of forming sheet by deformation because of its flexibility. In SPIF, the application of a circular end tool (spherical end pestle with no cutting edge) in a special SPIF machine or in a conventional CNC milling machine. Controlled by a digital program, the noncutting circular end tool moves in following a predefined trajectory to deform the workpiece sheet metal that is clamped on a special feature to format desired shape [1]. Especially in the manufacture of artificial joints and cranes for each personal patient in medicine, these products have to be made of Titanium for elimination of corrosion and deterioration. Although deformability of Titanium was performed by experimentation [2], simulation comparison of experimental results is necessary to verify the results and to build a simulation model for the product before manufacturing.

\section{THE SIMULATION OF DEFORMATION OF TITANIUM} SHEET

\subsection{CAD model for simulation}

The mechanical properties of commercial Titanium can be referred in [3]. The deformability of the method forming SPIF is determined by the maximum angle of deformation $\alpha_{\max }$. The largest shaping angle is the most important parameter, 
which represents the limited deformability of the material. The deformation angle is the maximum angle at which the material is not destroyed when formed by pestle [4].

$$
\alpha=\arccos \left(\frac{x}{R}\right)
$$

Wherein: $\boldsymbol{x}=z_{0}-z_{M_{1}}$
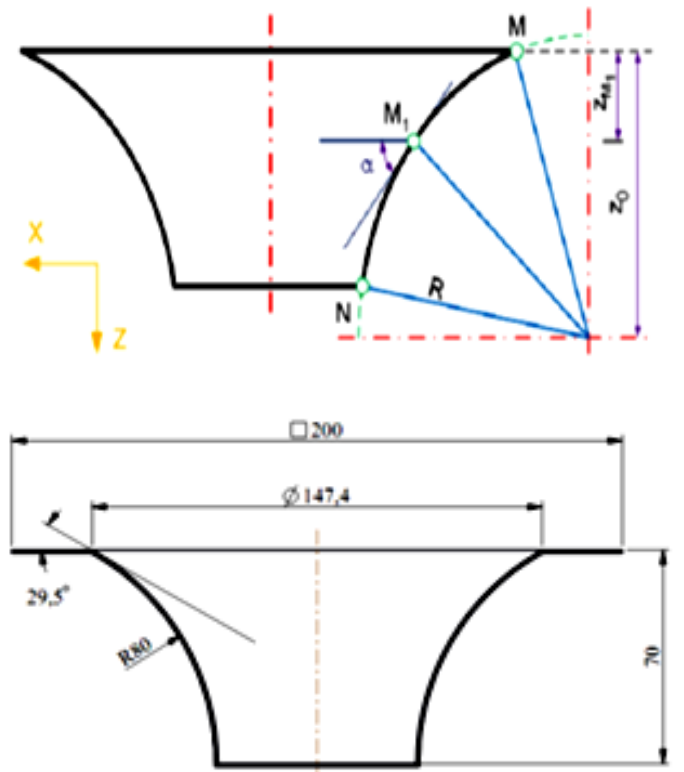

Figure 1: Selected lateral geometric of SPIF model and its real size

\subsection{Selection of the influence parameters in} simulation of Titanium sheet by HOT SPIF

As mentioned above, the four influence parameters and their limited values are represented in table 1 [5]

Table 1: Levels value of 4 influent parameters

\begin{tabular}{|c|l|l|l|l|l|}
\hline NO & \multicolumn{1}{|c|}{$\begin{array}{c}\text { Influent } \\
\text { parameters } \\
\text { (Input } \\
\text { parameter) }\end{array}$} & Sign & Unit & $\begin{array}{c}\text { Low } \\
\text { level }\end{array}$ & $\begin{array}{l}\text { High } \\
\text { level }\end{array}$ \\
\hline 1 & $\begin{array}{l}\text { The temperature } \\
\text { of titanium sheet }\end{array}$ & $\mathrm{T}$ & ${ }^{\circ} \mathrm{C}$ & 400 & 700 \\
\hline 2 & $\begin{array}{l}\text { Step in the } \\
\text { direction z of the } \\
\text { tool }\end{array}$ & $\Delta \mathrm{z}$ & $\mathrm{mm}$ & 0.3 & 0.6 \\
\hline 3 & $\begin{array}{l}\text { The velocity of the } \\
\text { tool }\end{array}$ & $\mathrm{V}_{\mathrm{xy}}$ & $\begin{array}{c}\mathrm{mm} / \\
\mathrm{min}\end{array}$ & 500 & 1500 \\
\hline 4 & Tool diameter & $\mathrm{D}$ & $\mathrm{mm}$ & 6 & 12 \\
\hline
\end{tabular}

With the above selected parameters, the study applies the Full Design of Experiment (DOE) 2 levels, the numbers of the experimental model are: $2^{4}=16$.

\subsection{Building an analysis model in Abaqus software Meshing and boundary conditions}

The element type of C3D6T are used to model with the initial selection of Titanium sheet that is selected as a deformation type with the size of 200x200x1mm and tool and feature are considered as analytical rigid. The Origin of coordinates is the sheet center [6]. Finite Element (FE) calculation considers 4 integration points in the thickness and is performed with ABAQUS/explicit. The meshing is shown in figure 3

The boundary conditions include a tool displacement, which is considered as a rigid body, and a clamping of all the external nodes. The value of the coefficient of friction is chosen equal to 0.1 according to stamping value found in the literature.

A typical explicit time step is presented in figure 2. The innovative part of this method concerns the way that the contact forces are taken into account. First, they are ignored when solving the equilibrium equation. Then, the error in the contact with the tool is computed geometrically. This depends only on the position $\underline{x_{1}}$ and velocity $\underline{\dot{x}_{1}}$ of the nodes close to the tool at the end of the time step. Finally, the nodal acceleration $\ddot{x}_{0}$ at the beginning of the time step can be corrected in order to meet the required contact conditions at the end of the time step. The correction on the acceleration, multiplied by the nodal mass, is equivalent to the contact forces.

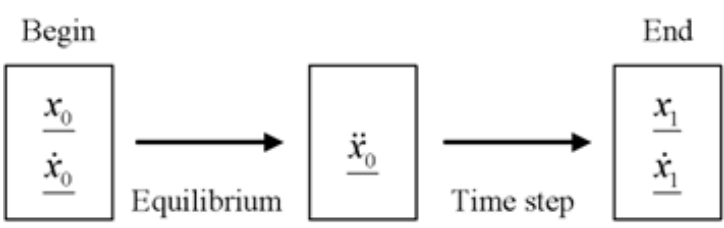

Figure 2: Dynamic explicit time step

In a first approach, elasto-plastic model is used. It includes a Von Mises yield criterion and an isotropic hardening law as presented in equations (2) and (3).

$$
f=\underline{\underline{\sigma}}_{e q}-R-R_{0}
$$




$$
R=Q\left(1-e^{-b \lambda}\right)
$$

With:

R: Isotropic hardening law

$\mathrm{R}_{0}$ : Yield strength

$\sigma_{\mathrm{eq}}$ : Von Mises equivalent stress

$\mathrm{Q}, \mathrm{b}$ : Materials parameters

The plastic multiplier, $\lambda$ is calculated from the consistency condition $f=\dot{f}=\mathrm{O}$. Thus, it is deduced from the relation $\frac{\partial f}{\partial \underline{\underline{\sigma}}}: \underline{\underline{\sigma}}+\frac{\partial f}{\partial R} \dot{R}=0$

$$
\lambda=H(f) \frac{1}{j}\left\langle\frac{\partial f}{\partial \underline{\underline{\sigma}}}: \underline{\underline{\dot{\sigma}}}\right\rangle \text { Wherein } \mathrm{h}=\mathrm{b}(\mathrm{Q}-\mathrm{R})
$$

In order to simulate the process of deforming Titanium we have to follow strictly the following module steps in Abacus software:

- Property module: to create the material and define its properties.

- Material properties:

- Condition of contact (module interaction)

- Boundary condition of base plate

The base plate is fixed in space (limited to 6 degrees of freedom). Selecting Symmetry/ Antisymmetric/Encastre

Boundary condition of sheet: 4 sides of the square sheet are fixed

Symmetry/Antisymmetric/Encastre type

The boundary condition of the tool: Tools allow to move in the direction $\mathrm{x}, \mathrm{y}, \mathrm{z}$ in the tool trajectory.

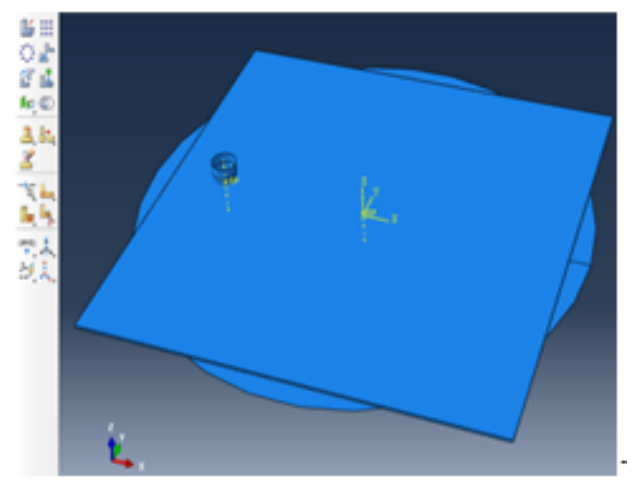

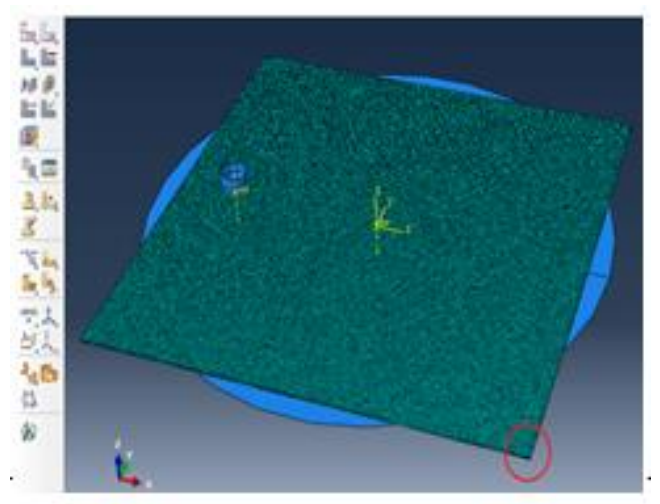

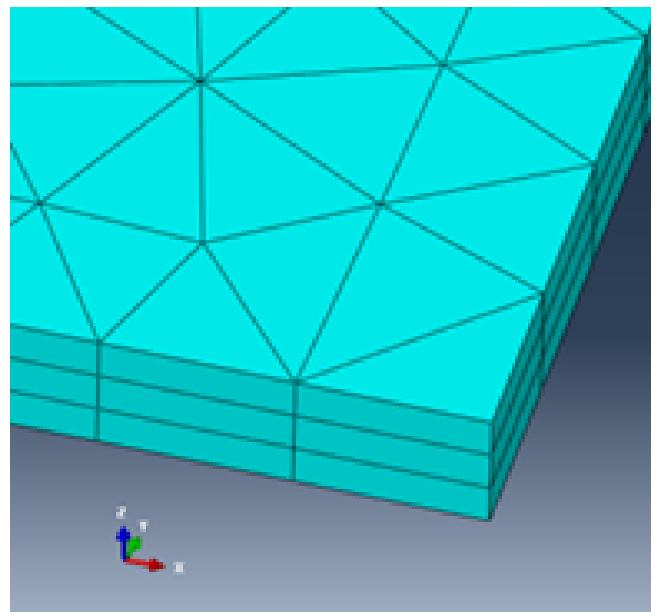

Figure 3: Initial simulation model and mesh model (with thickness)

\subsection{Analytical step (module Step)}

Selected type step is Dynamic, Temp-disp, and Explicit to see the effects of temperature. The time period parameters are interested with the reason of the total running time of the tool is equal to the time of the last step that is not the time of the computer processes but the total time of the steps.

$$
\begin{aligned}
t_{\text {total }} & =\frac{\text { Length of trajectory }}{\text { The velocity of the tool }} \\
& =\frac{\sum_{0}^{\mathrm{N}}\left(\sqrt{\left(\mathrm{x}_{\mathrm{i}+1}-\mathrm{x}_{\mathrm{i}}\right)^{2}+\left(\mathrm{y}_{\mathrm{i}+1}-\mathrm{y}_{\mathrm{i}}\right)^{2}+\left(\mathrm{z}_{\mathrm{i}+1}-\mathrm{z}_{\mathrm{i}}\right)^{2}}\right)}{\mathrm{V}_{\mathrm{xy}}}
\end{aligned}
$$

Create a job analysis and analysis (module job 


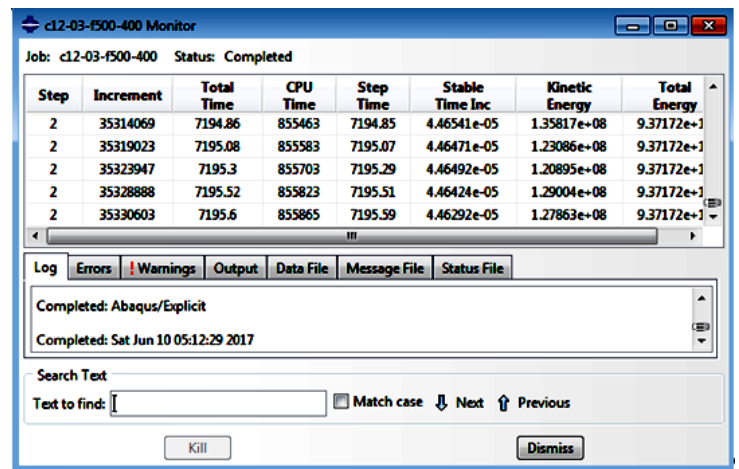

Figure 4: Managing the analytical process

There are 16 cases of the simulation model, here only shows the first case result image in table 2 . The results of other cases are summarized in table 3.

Table 2: The value of simulation for case 1

\begin{tabular}{|c|l|c|c|c|c|}
\hline NO & $\begin{array}{l}\text { Influent } \\
\text { parameter }\end{array}$ & Sign & Unit & Value & $\alpha\left({ }^{0}\right)$ \\
\hline 1 & $\begin{array}{l}\text { The } \\
\text { temperature } \\
\text { of titanium } \\
\text { sheet }\end{array}$ & $\mathrm{T}$ & ${ }^{\circ} \mathrm{C}$ & 400 & \\
\hline 2 & $\begin{array}{l}\text { Step depth } \\
\text { Vz of tool }\end{array}$ & $\Delta \mathrm{z}$ & $\mathrm{mm}$ & 0,3 & \multirow{2}{*}{$72.224^{0}$} \\
\hline 3 & $\begin{array}{l}\text { The } \\
\text { velocity of }\end{array}$ & $\mathrm{V}_{\mathrm{xy}}$ & $\mathrm{mm} /$ & 500 & \\
\cline { 1 - 2 } & $\begin{array}{l}\text { Tool } \\
\text { diameter }\end{array}$ & $\mathrm{D}$ & $\mathrm{mm}$ & 12 & \multicolumn{1}{|c|}{} \\
\hline
\end{tabular}

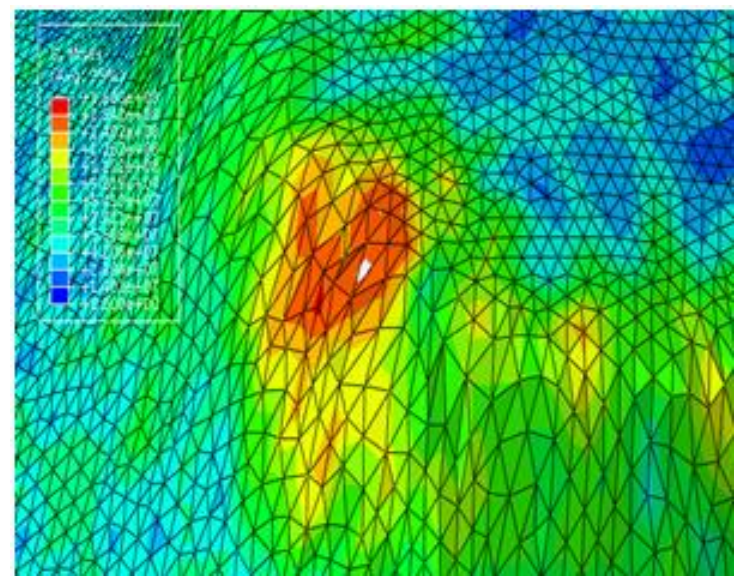

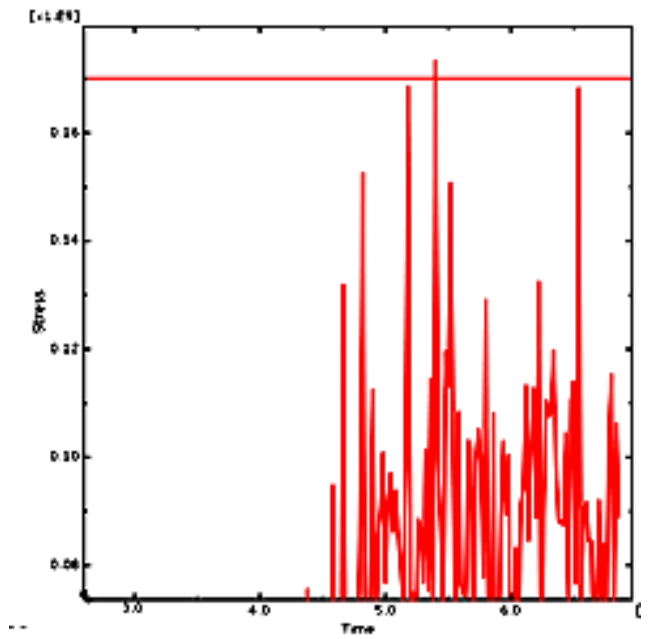

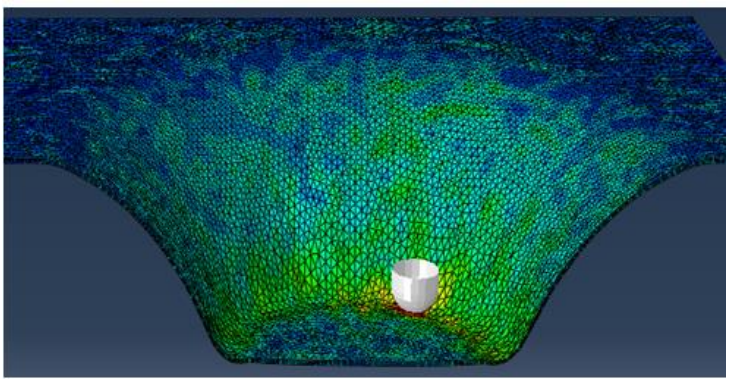

Figure 5: Left and middle: Location of torn sheet case 1 Right: Stress at the torn sheet position of case 1

According to the stress diagram (figure 5, Right) of the case being analyzed, the stress exceeds the tensile strength of $170 \mathrm{MPa}$ at step time of $\mathrm{t}=5400$ at the corresponding depth of -45.576 . Based on the formula (1) with $\mathrm{z}_{0}=70 \mathrm{~mm}, \mathrm{R}=80 \mathrm{~mm}$ we could calculate the distortion angle of $72.224^{\circ}$

\section{EXPERIMENTAL PROCESS OF FORMING TITANIUM SHEET BY HOT SPIF}

The experimental process is performed in SPIF machine in CAD-CAM workshop of National Key Laboratory of Digital Control and System Engineering (DCSELAB) with a designed feature for HOT SPIF. The experimental processes are performed with the same parameters of the simulation processes with the number of iteration is 3 for 16 experimental model. A total number of experimental models is $16 \times 3=48$ models. 

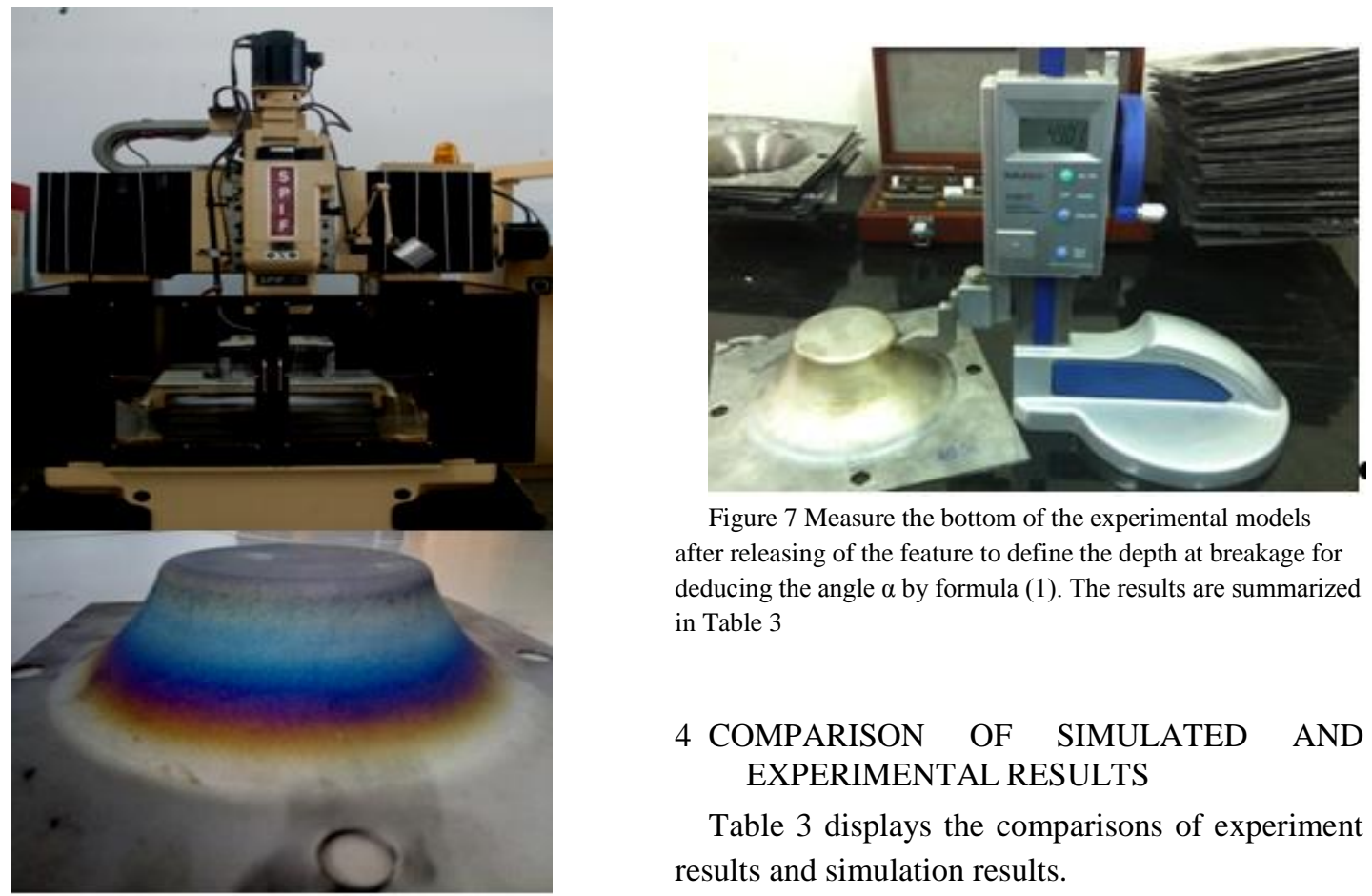

Figure 7 Measure the bottom of the experimental models after releasing of the feature to define the depth at breakage for deducing the angle $\alpha$ by formula (1). The results are summarized in Table 3

\section{COMPARISON OF SIMULATED AND EXPERIMENTAL RESULTS}

Table 3 displays the comparisons of experiment

Figure 6 Specialist SPIF machine with special feature for results and simulation results.

Table 3: Experiment and simulation results of HOT SPIF forming angles

\begin{tabular}{|c|c|c|c|c|c|c|c|}
\hline NO & $\mathrm{D}(\mathrm{mm})$ & $\begin{array}{c}\Delta \mathrm{z} \\
(\mathrm{mm})\end{array}$ & $\begin{array}{c}\mathrm{V}_{\mathrm{xy}} \\
(\mathrm{mm} / \mathrm{min})\end{array}$ & $\begin{array}{c}\mathrm{T} \\
\left({ }^{0} \mathrm{C}\right)\end{array}$ & $\begin{array}{c}\alpha\left({ }^{0}\right) \\
\text { simulation }\end{array}$ & $\begin{array}{c}\alpha\left({ }^{0}\right) \\
\text { experiment }\end{array}$ & Deviation \% \\
\hline 1 & 12 & 0.3 & 500 & 400 & 72.224 & 71.1 & 1.568474 \\
\hline 2 & 12 & 0.6 & 500 & 400 & 70.935 & 72.4 & 2.044162 \\
\hline 3 & 12 & 0.6 & 500 & 700 & 72.421 & 70.5 & 2.688198 \\
\hline 4 & 12 & 0.3 & 500 & 700 & 73.069 & 72.4 & 0.919784 \\
\hline 5 & 12 & 0.6 & 1500 & 700 & 71.119 & 71.7 & 0.813617 \\
\hline 6 & 12 & 0.3 & 1500 & 400 & 71.109 & 71 & 0.153403 \\
\hline 7 & 12 & 0.3 & 1500 & 700 & 71.386 & 71.3 & 0.120544 \\
\hline 8 & 12 & 0.6 & 1500 & 400 & 70.567 & 71 & 0.611724 \\
\hline 9 & 6 & 0.6 & 500 & 700 & 70.262 & 73.2 & 4.095858 \\
\hline 10 & 6 & 0.3 & 1500 & 400 & 69.994 & 70 & 0.008572 \\
\hline 11 & 6 & 0.6 & 500 & 400 & 69.915 & 69 & 1.317352 \\
\hline 12 & 6 & 0.3 & 500 & 400 & 69.907 & 70.4 & 0.702745 \\
\hline 13 & 6 & 0.6 & 1500 & 400 & 68.716 & 72 & 4.667557 \\
\hline 14 & 6 & 0.3 & 500 & 700 & 70.771 & 73.1 & 3.237623 \\
\hline 15 & 6 & 0.6 & 1500 & 700 & 69.228 & 70 & 1.108972 \\
\hline 16 & 6 & 0.3 & 1500 & 700 & 70.251 & 71.1 & 1.201265 \\
\hline
\end{tabular}


The difference between Simulation and Experiment results is shown in the diagram in figure 7 .

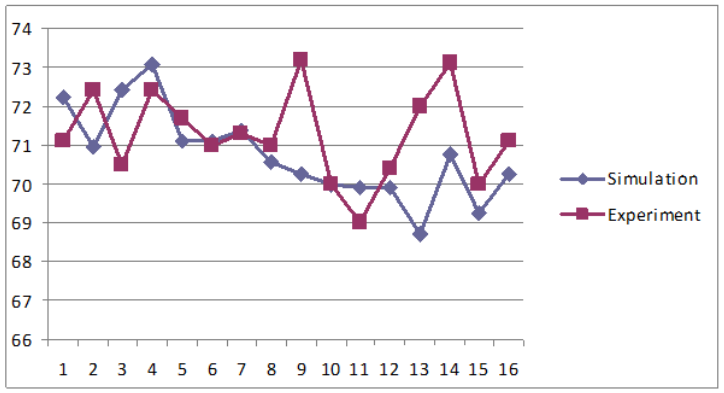

Figure 8 Comparison of simulation and experiment of angle of deformation (vertical axis) through the number of models (horizontal axis)

\section{CONSIDERATION:}

Simulation values with a $12 \mathrm{~mm}$ tool diameter are greater than or equal to the experiment, simulation values with a diameter of $6 \mathrm{~mm}$ are smaller than the experimental ones.

All deviations are less than 5\%. This tolerance is acceptable for simulations close to experiment.

\section{POST SIMULATION: STATISTICS RESULT OF TITANIUM HOT SPIF}

\section{Regressive equation}

The regressive equation of deformation ability of Titanium under the influence of 4 input parameters by Design Expert software:

$$
\begin{aligned}
\alpha & =70,732+0,875 D-0,337 \Delta z-0,436 V_{x y} \\
& +0,335 T-0,010 D \Delta z-0,126 D V_{x y} \\
& +0,064 D T-0,052 \Delta z V_{x y}+0,027 \Delta z T \\
& -0,135 V_{x y} T+0,197 D \Delta z V_{x y}+0,084 D \Delta z T \\
& +0,056 D V_{x y} T+0,039 \Delta z V_{x y} T-0,081 D \Delta z V_{x y} T
\end{aligned}
$$

The Design-Expert software help to analyses the mutual influences of 2 in 4 parameters to the formability (angle $\alpha$ ). Figure 8 illustrates the mutual influences of deformation angle $\alpha$ to 2 in 4 influenced parameters. Consideration the results:

- The forming angle $\alpha$ is a positive correlation to the tool diameter.

- The forming angle $\alpha$ is a negative correlation between the feed rate $V_{x y}$ and step depth $V_{z}$ of the tool.

- The forming angle $\alpha$ is a positive correlation to the temperature $\mathrm{T}$.

Analyses of the influence of input parameters

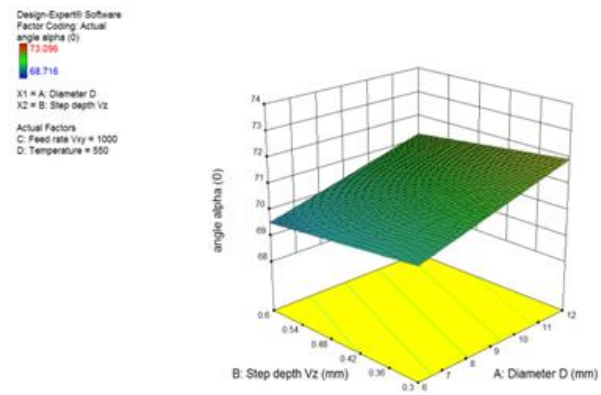

1.Influence of Step depth $V_{z}$ and diameter $D$
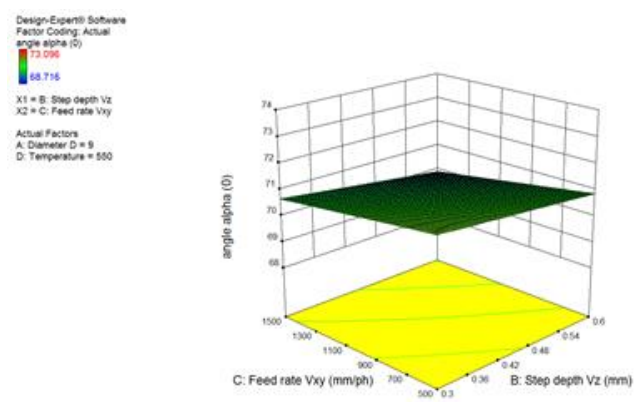

2.Influence of Feed rate Vxy and Step depth $V z$
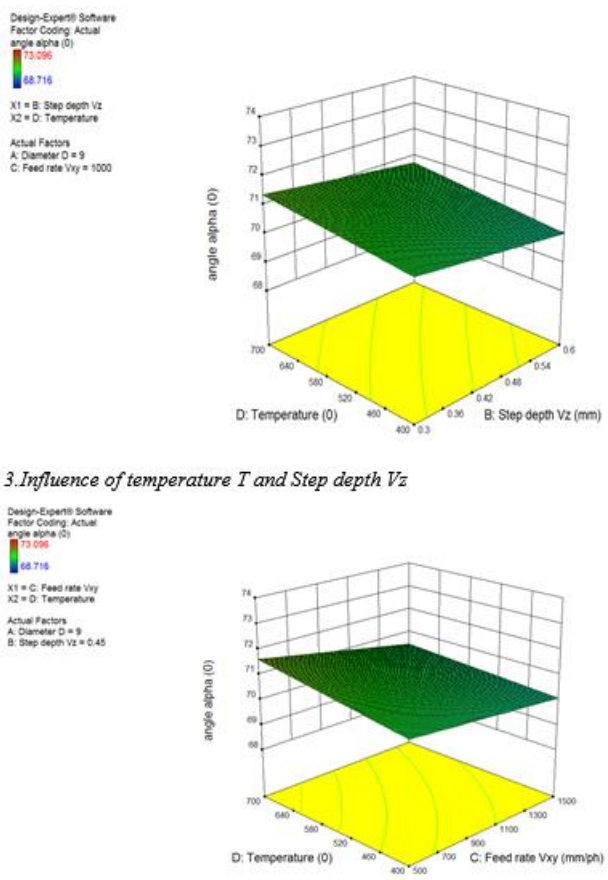

4.Influence of temperature $T$ and Feed rate Vxy

Figure 9: Influence of 4 parameters: Step depth Vz, Feed rate Vxy, diameter $\mathrm{D}$ and temperature $\mathrm{T}$ to the formability angle $\alpha$ 


\section{CONCLUSIONS}

The simulation and experimental results show that the diameter $\mathrm{D}$ of the tool and temperature $\mathrm{T}$ of the Titanium sheet are a positive correlation to the ability of deformation (angle $\alpha$ ) in the meanwhile the Step depth Vz and the Feed rate Vxy of are negative to the angle. In reality, with the purpose of increasing the ability of deformation $\alpha$, we should use the bigger tool at high temperature but the diameter D of the tool cannot be increased freely because there is also the increase of force of forming and the SPIF technology could not perform the small radius of the product. The increase in the temperature $\mathrm{T}$ of the sheet is influenced by the mechanical properties of the tool and it must be limited. The decrease of feed rate and step depth will engender to the decrease of productivity of the process. In the future, it is possible to perform simulations before processing and will save the cost of testing, saving time and cost of machining.

\section{REFERENCES}

[1] Yogesh Kumar and Santosh Kumar "Incremental Sheet Forming (ISF)", ISBN 978-81-322-2354-2 Springer 2014.

[2] W. G. GUO and J. Y. CHENG "Mechanical Properties And Deformation Mechanisms Of A Commercially Pure Titanium S. NematNasser". Acta Metallurgica Inc. Published by Elsevier Science Ltd.47, No. 13, pp. 3705-3720, 1999.

[3] C. Veiga, J.P. Davim, A.J.R. Loureiro "Properties And Applications Of Titanium Alloys: A Brief Review", Advance Materials Science, 32-133-148, 2012

[4] Mladomir Milutinovića, Robert Lenđela Michal Potranb, Dragiša Vilotića, Plavka Skakuna, Miroslav Plančaka "Application of Single Point IncrementalForming For Manufacturing of Denture Base", Journal for Technology of Plasticity, Vol. 39 (2014), Number 2.

[5] Nguyen Thanh Nam, Phan Dinh Tuan, Vo Van Cuong, Le Khan Dien, Nguyen Thin Binh, Le Trang Hien, "Research on The Forming Angle of A1050-H14 AluminumMaterial Processed by Using
Single Point IncrementalForming Technology (SPIF)", Science \& Technology Development, Vol 12, No.16 - 2009.

[6] Adrian José Benita Lozano, Gabriel Jaime PARAMBermudez, Frank Alexander Bustamante Correa "Comparative Analysis between the SPIF andDPIF Variants for Die-less Forming Processfor an Automotive Workpiece", Inge Cuc, vol. 11 no. 2, pp 6873, July - December, 2015.

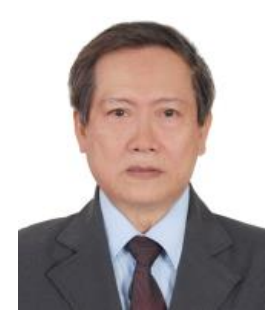

Le, Khanh Dien received his M.S degree in Ho Chi Minh City University of Technology - VNU-HCM. He is a lecturer in the Faculty of Mechanical Engineering, Ho Chi Minh City University of Technology - VNU-HCM. His current interests include machine design, SPIF, TPIF

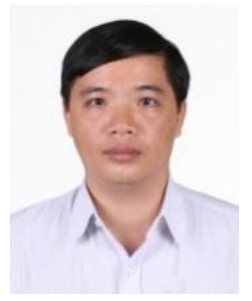

Pham Huy Hoang received a Ph.D. degree from Nanyang Technological University, Singapore in 2006. He is an Associate Professor in the Faculty of Mechanical Engineering, Ho Chi Minh City University of Technology - VNU-HCM, Vietnam. Major research areas include kinetic and mechanical dynamics, elastic structures, and diagnostic techniques.

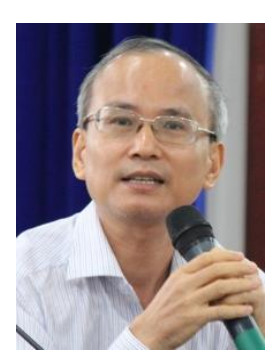

Nguyen Thanh Nam is a lecturer, Professor at Ho Chi Minh City University of Technology - VNU-HCM. He received his Ph.D. in mechanical engineering from Technical University, Sofia, Bulgaria. $\mathrm{He}$ is currently a director of the National Key Lab of Digital control and Systems Engineering (DCSELAB). 


\title{
Nghiên cứu khả năng tạo hình vật liệu titan sử dụng công nghệ tạo hình gia công đơn điểm (HOT SPIF) bằng phương pháp mô phỏng số
}

\author{
Trần Trọng Hỷ, Nguyễn Tấn Hùng, Võ Tuyển, Lê Khánh Điền, Phạm Huy Hoàng, \\ Nguyễn Thanh Nam, Nguyễn Ngọc Phương
}

Tóm tắt- Phương pháp tạo hình gia công đơn điểm (Hot single point incremental forming HOT SPIF) là công nghệ mới để tạo hình các loại vật liệu tấm ở nhiệt độ cao, đặc biệt là các loại vật liệu có trở lực biến dạng cao mà các phương pháp gia công ở nhiệt độ thường khó thực hiện được, phổ biến hiện nay là Titan. Nghiên cứu này trình bày phương pháp mô phỏng để xác định khả năng biến dạng của vật liệu ở nhiệt độ cao, trong đó ảnh hưởng của các thông số đường kính dụng cụ $\mathrm{D}(\mathrm{mm})$, bước tiến theo phương $\mathrm{z}$ của dụng cụ $\Delta \mathrm{z}(\mathrm{mm})$, tốc độ chạy dụng cụ $V x y\left(\mathrm{~mm} /\right.$ phút), nhiệt độ $\mathrm{T}\left({ }^{0} \mathrm{C}\right)$ đến góc tạo hình $\alpha_{\max }$ là nội dung chính của bài báo. Quá trình phân tích ảnh hưởng của các thông số công nghệ được tiến hành bằng việc xây dựng mô hình phần tử hữu hạn, phân tích mô hình, xác định góc biến dạng giới hạn và so sánh độ chính xác của mô hình phần tử hữu hạn (FEA) với mô hình bằng phần mềm máy tính (CAD). Kết quả nghiên cứu sẽ cung cấp các chế độ gia công tạo hình cho quá trình HOT SPIF trên tấm titan để đạt được góc tạo hình phù hợp nhất.

Tù khoá - HOT SPIF, biến dạng, Titan tấm, khả năng biến dạng, mô hình FEA, CAD. 